\title{
Cluster Analysis of the Competency of Engineering Teachers
}

\author{
Xingfeng $\mathrm{Liu}^{1, \mathrm{a}}$ and Tiansong Zhou ${ }^{2, \mathrm{~b}}$ \\ ${ }^{1,2}$ School of Management, Wuhan University of Technology, P. R. China, 430070 \\ a249763651@qq.com, ${ }^{\text {b3 } 346822862 @ q q . c o m ~}$
}

Keywords: Cluster analysis; Evaluation of competency; Engineering teachers

\begin{abstract}
On the basis of introduction of cluster analysis, analytic hierarchy process (AHP for abbreviation) is applied to evaluate the competency of engineering teachers in $\mathrm{W}$ university. Then cluster analysis is made by the use of statistical software SPSS19 .0 to evaluate the sample engineering teachers from their self-assessment competency questionnaires in accordance with Kmeans method. From the results of cluster analysis, it is found that the results is approximately the same with the results of AHP with the advantage of broader inclusion, showing that the cluster analysis can more scientifically classify the competency of engineering teachers and provide basis for decision making in universities as well.
\end{abstract}

\section{Introduction}

In the field of socio-economy, there are a great number of problems of classifications and classification structure models. Thus cluster analysis is a useful method of classification of individuals or objects to make similarities stronger within the same types than that within other types[1-2]. The aim of cluster analysis is to maximize homogeneity as well as the heterogeneity among the same class of objects[3-4].

Previous studies mainly rely on the experience and expertise to deal with qualitative classifications, resulting in many subjective or arbitrary classifications which are not good reminders to reveal the inherent nature of the differences and links of objective things. As for multi-factor or multi-index classifications, qualitative classifications are more difficult to achieve accuracy. In order to overcome the shortcomings of the qualitative classifications, mathematics is gradually introduced into the taxonomy to form the numerical taxonomy. And with the introduction of multivariate analysis, cluster analysis is used to classify cases or variables later [5-6].

\section{Competency Evaluation of Engineering Teachers by Means of AHP}

According to the requirements of full-time engineering teachers in universities, performance evaluation of engineering teachers are designed to include four guideline layers of quality, knowledge, teaching and research capability and personal feature[7-9]. What's more, these four guideline layers include 24 different indexes to constitute the index layers so as to form a complete performance evaluation system of engineering teachers. For the four guideline elements, pairwise comparison judgment matrix $\left(\mathrm{U}_{\mathrm{ij}}\right) 4 \times 4$ can be obtained and judgment matrix is indicated in the form of Table 1. Among them, the $U_{i j}$ represents the importance of $U_{i}$ and $U_{j}$ which are compared with target value. By means of 1-9 scale method proposed by Satty, the importance of indicators is scale-divided[10]. Apart from that, weighting of indicators are judged by experts according to their backgrounds and experiences. The scale and the results of relative importance of index are obtained from averaging correction, judgment matrix is established. After calculation, judgment matrix has passed consistency test, the results are shown in Table 1.

Table 1 Performance target - index layer judgment matrix of engineering teachers in universities

\begin{tabular}{|c|c|c|c|c|}
\hline $\mathrm{U}$ & $\mathrm{U}_{1}$ & $\mathrm{U}_{2}$ & $\mathrm{U}_{3}$ & $\mathrm{U}_{4}$ \\
\hline $\mathrm{U}_{1}$ & $\mathrm{U}_{11}$ & $\mathrm{U}_{12}$ & $\mathrm{U}_{13}$ & $\mathrm{U}_{14}$ \\
\hline $\mathrm{U}_{2}$ & $\mathrm{U}_{21}$ & $\mathrm{U}_{22}$ & $\mathrm{U}_{23}$ & $\mathrm{U}_{24}$ \\
\hline $\mathrm{U}_{3}$ & $\mathrm{U}_{31}$ & $\mathrm{U}_{32}$ & $\mathrm{U}_{33}$ & $\mathrm{U}_{34}$ \\
\hline $\mathrm{U}_{4}$ & $\mathrm{U}_{41}$ & $\mathrm{U}_{42}$ & $\mathrm{U}_{43}$ & $\mathrm{U}_{44}$ \\
\hline
\end{tabular}


Table 2 calculation results of consistency check

\begin{tabular}{|l|c|c|c|c|}
\hline & $\mathrm{CR}$ & $\lambda \max$ & $\mathrm{CI}$ & $\mathrm{RI}$ \\
\hline target $\mathrm{U}_{-}$guideline $\mathrm{U}_{\mathrm{i}}$ & 0.0115 & 4.0310 & 0.0103 & 0.9 \\
\hline quality $\mathrm{U}_{1}$-index layer & 0.0031 & 7.0247 & 0.0041 & 1.32 \\
\hline knowledge $\mathrm{U}_{2}$-index layer & 0.0032 & 3.0037 & 0.0018 & 0.58 \\
\hline teaching and research capabilities $\mathrm{U}_{3}$-index layer & 0.0559 & 7.4431 & 0.0739 & 1.32 \\
\hline personal features $\mathrm{U}_{4}$-index layer & 0.0026 & 7.0203 & 0.0034 & 1.32 \\
\hline
\end{tabular}

$\mathrm{AW}=\lambda_{\max } \mathrm{W}$ is used to solve $\lambda \max$ corresponding feature vector $\mathrm{W}$ of $\lambda \max$, which is normalized, namely the weighting coefficient of the corresponding index of the same level for some indicator of the top level. Root method is used, calculating method are seen in formula (1-1), formula (1-2) and (1-3). The results are in table 3.

(1)To calculate the product $\mathrm{M}_{\mathrm{i}}$ of the elements of each row of judgment matrix

$$
M_{i}=\prod_{j=1}^{n} a_{i j}(i=1,2, \cdots, n)
$$

(2) To calculate n-th root $\overline{\mathrm{W}}_{\mathrm{I}}$ of $\overline{\mathrm{W}}_{\mathrm{i}}$

$$
\bar{W}_{i}=\sqrt[n]{M_{i}}
$$

(3) To normalize the vector $\overline{\mathrm{W}}=\overline{\mathrm{W}}_{1}, \overline{\mathrm{W}}_{2}, \ldots, \overline{\mathrm{W}}_{\mathrm{n}}^{\mathrm{T}}$

$W_{i}=\bar{W}_{i} / \sum_{j=1}^{n} \bar{W}_{j}$

Therefore, $\mathrm{W}=\mathrm{W}_{1}, \mathrm{~W}_{2}, \ldots, \mathrm{W}_{\mathrm{n}}^{\mathrm{T}}$ is the feature vector of seeking weight.

\begin{tabular}{|c|c|c|c|c|c|}
\hline & first level & $\begin{array}{c}\text { weight } \\
\mathrm{W}_{\mathrm{i}}\end{array}$ & second level & $\begin{array}{c}\text { stratification } \\
\text { weight }\end{array}$ & $\begin{array}{c}\text { total } \\
\text { weight } \\
\mathrm{W}_{\mathrm{ij}}\end{array}$ \\
\hline \multirow{19}{*}{$\mathrm{U}$} & \multirow{7}{*}{ quality $\mathrm{U}_{1}$} & \multirow{7}{*}{0.2776} & spirit of dedication $\mathrm{U}_{11}$ & 0.0729 & 0.0202 \\
\hline & & & benevolent acceptance $U_{12}$ & 0.0706 & 0.0196 \\
\hline & & & integrity $\mathrm{U}_{13}$ & 0.2151 & 0.0597 \\
\hline & & & social responsibility $\mathrm{U}_{14}$ & 0.1320 & 0.0366 \\
\hline & & & student orientation $\mathrm{U}_{15}$ & 0.0706 & 0.0196 \\
\hline & & & spread of positive energy $U_{16}$ & 0.0688 & 0.0191 \\
\hline & & & role model $\mathrm{U}_{17}$ & 0.3699 & 0.1027 \\
\hline & \multirow{3}{*}{ knowledge $\mathrm{U}_{2}$} & \multirow{3}{*}{0.4668} & professional expertise $U_{21}$ & 0.3090 & 0.1442 \\
\hline & & & research method $U_{22}$ & 0.5816 & 0.2715 \\
\hline & & & engineering practice $U_{23}$ & 0.1095 & 0.0511 \\
\hline & \multirow{7}{*}{$\begin{array}{l}\text { Teaching and } \\
\text { scientific } \\
\text { research } \\
\text { capability } \mathrm{U}_{3}\end{array}$} & \multirow{7}{*}{0.1603} & study apperception $\mathrm{U}_{31}$ & 0.0442 & 0.0071 \\
\hline & & & teamwork $\mathrm{U}_{32}$ & 0.2139 & 0.0343 \\
\hline & & & theory with practice $\mathrm{U}_{33}$ & 0.1251 & 0.0201 \\
\hline & & & organization of teaching $\mathrm{U}_{34}$ & 0.0592 & 0.0095 \\
\hline & & & innovation and exploration $\mathrm{U}_{35}$ & 0.1009 & 0.0162 \\
\hline & & & cultivation and instruction $\mathrm{U}_{36}$ & 0.0802 & 0.0129 \\
\hline & & & speech expression $U_{37}$ & 0.3766 & 0.0604 \\
\hline & \multirow{2}{*}{$\begin{array}{c}\text { personal } \\
\text { feature } U_{4}\end{array}$} & \multirow{2}{*}{0.0953} & love for students $\mathrm{U}_{41}$ & 0.2371 & 0.0226 \\
\hline & & & respect to peopleU $U_{42}$ & 0.1287 & 0.0123 \\
\hline
\end{tabular}

Table 3 Total weight of each element 
Table 3, cont.

\begin{tabular}{|l|l|l|c|c|}
\hline \multirow{3}{*}{} & enlightenment $\mathrm{U}_{43}$ & 0.1287 & 0.0123 \\
\cline { 3 - 4 } & responsibility $\mathrm{U}_{44}$ & 0.2371 & 0.0226 \\
\cline { 3 - 4 } & confidence $\mathrm{U}_{45}$ & 0.0699 & 0.0067 \\
\hline & persistence $\mathrm{U}_{46}$ & 0.0699 & 0.0067 \\
\hline & enterprise $\mathrm{U}_{47}$ & 0.1287 & 0.0123 \\
\hline
\end{tabular}

In order to facilitate research, only 34 questionnaires of self-evaluation of engineering teachers are selected as samples in W University. Results are calculated according to the weight determined in Table 3 and the results of performance evaluation of AHP are shown in Table 4.

Table 4 Results of performance evaluation of AHP in W university (self competency evaluation of 34 engineering teachers)

\begin{tabular}{|c|c|c|c|c|c|}
\hline $\begin{array}{l}\text { No. of } \\
\text { teachers }\end{array}$ & sex & age & title & $\begin{array}{c}\text { score } \\
\text { of evaluation }\end{array}$ & percentile score \\
\hline ZP001 & Male & 38 & lecturer & 8.171236 & 90.79151 \\
\hline ZP002 & Male & 53 & associate professor & 8.057526 & 89.52807 \\
\hline ZP003 & Male & 46 & associate professor & 8.051344 & 89.45938 \\
\hline ZP004 & Male & 36 & lecturer & 8.384824 & 93.16471 \\
\hline ZP005 & Male & 39 & associate Professor & 7.957929 & 88.42143 \\
\hline ZP006 & Male & 36 & lecturer & 8.261267 & 91.79186 \\
\hline ZP007 & Male & 35 & lecturer & 8.625388 & 95.83764 \\
\hline ZP008 & Male & 36 & associate professor & 7.031283 & 78.12537 \\
\hline ZP009 & Male & 38 & associate professor & 7.072217 & 78.58019 \\
\hline ZP010 & Male & 45 & professor & 8.247954 & 91.64393 \\
\hline ZP011 & Male & 32 & lecturer & 7.214198 & 80.15776 \\
\hline ZP012 & Male & 43 & professor & 7.595864 & 84.39849 \\
\hline ZP013 & Male & 48 & professor & 8.536483 & 94.84981 \\
\hline ZP014 & Male & 44 & associate professor & 7.567526 & 84.08362 \\
\hline ZP015 & Male & 31 & lecturer & 8.492185 & 94.35761 \\
\hline ZP016 & Male & 53 & associate professor & 8.385913 & 93.17681 \\
\hline ZP017 & Male & 55 & professor & 7.743958 & 86.04398 \\
\hline ZP018 & Male & 38 & associate professor & 8.560462 & 95.11624 \\
\hline ZP019 & Male & 44 & professor & 7.810079 & 86.77866 \\
\hline $\mathrm{ZP020}$ & Male & 48 & associate professor & 8.185521 & 90.95023 \\
\hline ZP021 & Male & 36 & lecturer & 8.419903 & 93.55448 \\
\hline $\mathrm{ZP} 022$ & Female & 35 & lecturer & 8.610484 & 95.67204 \\
\hline ZP023 & Female & 48 & professor & 7.95943 & 88.43811 \\
\hline ZP024 & Female & 33 & assistant & 8.210952 & 91.2328 \\
\hline ZP025 & Female & 32 & lecturer & 7.241441 & 80.46046 \\
\hline ZP026 & Female & 44 & associate professor & 8.124543 & 90.2727 \\
\hline $\mathrm{ZP} 027$ & Female & 36 & assistant & 8.378991 & 93.0999 \\
\hline ZP028 & Female & 32 & assistant & 8.476565 & 94.18406 \\
\hline ZP029 & Female & 58 & professor & 7.827661 & 86.97401 \\
\hline $\mathrm{ZP030}$ & Female & 33 & lecturer & 7.982569 & 88.69521 \\
\hline ZP031 & Female & 34 & assistant & 7.996101 & 88.84557 \\
\hline ZP032 & Female & 40 & associate Professor & 8.16841 & 90.76011 \\
\hline ZP033 & Female & 37 & lecturer & 7.610157 & 84.5573 \\
\hline ZP034 & Female & 34 & assistant & 8.007975 & 88.9775 \\
\hline
\end{tabular}


According to the general percentile method, classification is determined as follows: 60 points or less than 60 points are rated as "unqualified"; 60 to 70 points are rated as "qualified", 70 to 80 points are rated as "medium"; 80 to 90 points are rated as "good" and 90 points or more than 90 points are rated as "excellent", the assessment results of these 34 engineering teachers are shown in Fig. 1.

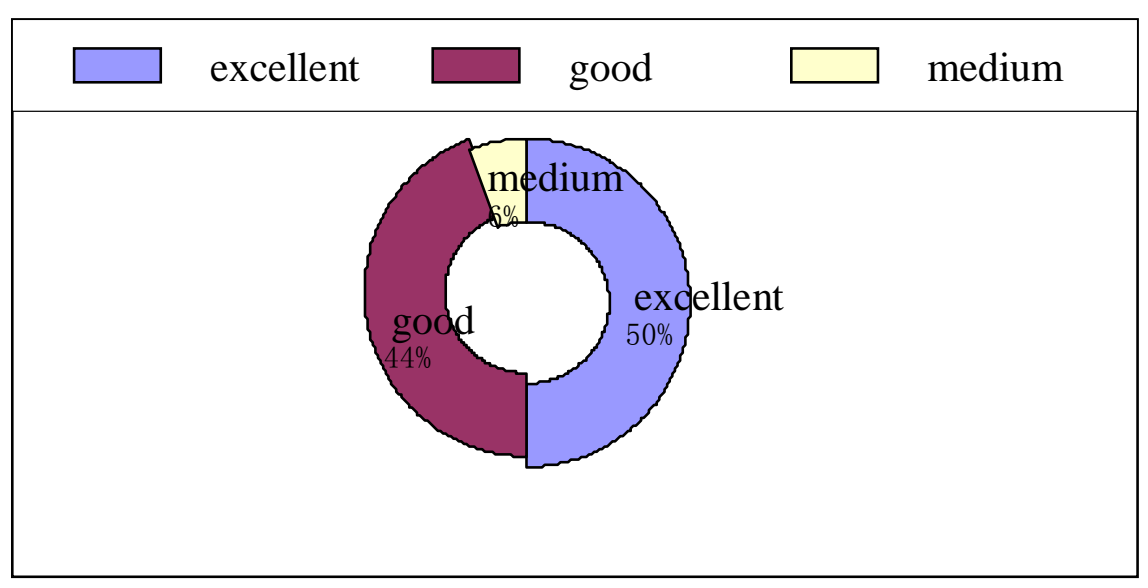

Figure 1. Percentile of evaluation results

\section{Case of Cluster Analysis of Competency Level of Engineering Teachers in W university}

Application of statistics SPSS19.0 software on self-assessment questionnaires of engineering teachers according to the cluster analysis of K-means method, the number of clusters is set to 3 levels of "excellent", "good" and "medium", the following clustering results can be obtained in Table 5.

Table 5 Evaluation grade of clustering of self-assessment questionnaire of engineering teachers

\begin{tabular}{|l|l|l|l|c|}
\hline $\begin{array}{l}\text { No.of } \\
\text { teachers }\end{array}$ & $\begin{array}{l}\text { evaluation } \\
\text { score by AHP }\end{array}$ & $\begin{array}{l}\text { evaluation grade } \\
\text { by AHP }\end{array}$ & $\begin{array}{l}\text { Clustering of } \\
\text { K- means }\end{array}$ & $\begin{array}{l}\text { mark of similarities and } \\
\text { differences(same=0; } \\
\text { different=1) }\end{array}$ \\
\hline ZP001 & 90.79151 & excellent & I (excellent) & 0 \\
\hline ZP002 & 89.52807 & good & II (good) & 0 \\
\hline ZP003 & 89.45938 & good & I (excellent) & 1 \\
\hline ZP004 & 93.16471 & excellent & I (excellent) & 0 \\
\hline ZP005 & 88.42143 & good & II (good) & 0 \\
\hline ZP006 & 91.79186 & excellent & I (excellent) & 0 \\
\hline ZP007 & 95.83764 & excellent & I (excellent) & 0 \\
\hline ZP008 & 78.12537 & medium & III (medium) & 0 \\
\hline ZP009 & 78.58019 & medium & II (good) & 0 \\
\hline ZP010 & 91.64393 & excellent & I (excellent) & 1 \\
\hline ZP011 & 80.15776 & good & II (good) & 0 \\
\hline ZP012 & 84.39849 & good & I (excellent) & 1 \\
\hline ZP013 & 94.84981 & excellent & I (excellent) & 0 \\
\hline ZP014 & 84.08362 & good & I (excellent) & 0 \\
\hline ZP015 & 94.35761 & excellent & I (excellent) & 1 \\
\hline ZP016 & 93.17681 & excellent & I (excellent) & I (excellent) \\
\hline ZP017 & 86.04398 & good & & \\
\hline
\end{tabular}


Table 5, cont.

\begin{tabular}{|l|l|l|l|l|}
\hline ZP018 & 95.11624 & excellent & I (excellent) & 0 \\
\hline ZP019 & 86.77866 & good & I (excellent) & 1 \\
\hline ZP020 & 90.95023 & excellent & I (excellent) & 0 \\
\hline ZP021 & 93.55448 & excellent & I (excellent) & 0 \\
\hline ZP022 & 95.67204 & excellent & I (excellent) & 0 \\
\hline ZP023 & 88.43811 & good & I (excellent) & 1 \\
\hline ZP024 & 91.2328 & excellent & I (excellent) & 0 \\
\hline ZP025 & 80.46046 & good & I (excellent) & 1 \\
\hline ZP026 & 90.2727 & excellent & I (excellent) & 0 \\
\hline ZP027 & 93.0999 & excellent & I (excellent) & 0 \\
\hline ZP028 & 94.18406 & excellent & I (excellent) & 0 \\
\hline ZP029 & 86.97401 & good & I (excellent) & 1 \\
\hline ZP030 & 88.69521 & good & II (good) & 0 \\
\hline ZP031 & 88.84557 & good & I (excellent) & 1 \\
\hline ZP032 & 90.76011 & excellent & I (excellent) & 1 \\
\hline ZP033 & 84.5573 & good & I (excellent) & I (excellent) \\
\hline ZP034 & 88.9775 & good & &
\end{tabular}

From the results shown in table 5, the results of cluster analysis for competency of engineering teachers is $68 \%$ the same compared with the results of AHP method in accordance with the results of samples. What's more, it is worth mentioning that the difference of the rest percentile is that the classification of levels by clustering of $\mathrm{K}$ - means is one more level higher than those by AHP method. In other words, some of the competency results by AHP method classified as the level of "good" are classified as the level of "excellent" by clustering of $\mathrm{K}$ means in general. Some of the competency results by AHP method classified as the level of "medium" are classified as the level of "good" by clustering of $\mathrm{K}$ means in general. In addition, the scores of these competency results calculated by clustering of $\mathrm{K}$ means, i.e those scores which are different from those of AHP method are relatively higher compared with scores classified as the level of "medium" or "good" by AHP method. To some degree, the method of clustering of $\mathrm{K}$ means is more inclusive and general for embracing topper levels. As for the overall differences of all indicators, clustering analysis does not consider the importance and weight of indicators as some indicators are relatively important or unimportant in the eyes of some people, therefore clustering analysis is somewhat different with AHP method for the reason that weights which may be subjective are considered in the AHP method.

\section{Conclusion}

In the study of competency of engineering teachers in universities, the score of competency evaluation is usually a relative score. In order to obtain the specific results, the results of evaluation often requires division level, such as classification of four levels of "excellent", "good", "qualified" and "unqualified". Methods of traditional classification have strict borders. For instance, if students' achievements are classified according to levels of "excellent", "good", "medium", "qualified" and "unqualified"," there is only 1 point difference between 59 points and 60 points, but the classification is quite different as the "unqualified" for 59 points and "qualified" for 60 points. The gap of "good level" between 89 points and 90 points is far less than the gap of "good level" between 80 points and 90 points. Therefore, in terms of evaluation of the competency of engineering teachers, according to five division levels of "excellent", "good", "medium", "qualified" and "unqualified", the above problems can also occur. Cluster analysis can avoid this kind of 
problem. As the data mining technology in the era of big data, clustering analysis is used not only to classify the competence level of engineering teachers but also provide basis for decision making for competence- grading of all teachers in other universities. Therefore, it is of theoretical and practical significance for the study in this paper.

\section{References}

[1] Chang D X, Zhang X D, Zheng C W. A genetic algorithm with gene rearrangement for K-means clustering[J]. Pattern Recognition, 2009, 42(7): 1210-1222.

[2] Chen X M, Liu W Q, Qiu H N, Lai J H. APSCAN: A parameter free algorithm for clustering [J]. Pattern Recognition Letters, 2011, 32(7): 973-986.

[3] Tasdemir K, Milenov P, Tapsall B. Topology-based hierarchical clustering of self-organizing maps[J]. IEEE Transactions on Neural Networks, 2011, 22(3): 474-485.

[4] Efendi N, Cagin K C. OWA-based linkage method in hierarchical clustering: application on phylogenetic trees [J]. Expert Systems with Applications, 2011, 38(10): 12685-12690.

[5] Kwedlo W. A clustering method combining differential evolution with the K-means algorithm[J]. Pattern Recognition Letters, 2011, 32(12): 1613-1621.

[6] Tang D M, Zhu Q X, Yang F. A poison-based adaptive Affinity Propagation clustering for sage data[J]. Computational Biology and Chemistry, 2010, 34(1): 63-70.

[7] Tai Sik Lee, Du-Hwan Kim, Dong Wook Lee et al. A competency model for project construction team and project control Team[J]. KSCE Journal of Civil Engineering, 2011, 15(5): 781-792.

[8] Morrison. Enhancing professional practice: A Framework for teaching [J].Alexandr VA 2012, (51):4-5.

[9] Lewis. Understanding human competence at work: an interpretative approach[J]. Academy of Management Journal, 2014,(3):43.

[10]T.L.Saaty. Decision-making with the AHP: Why is the principal eigenvector necessary [J]. European Journal of Operational Research, 2003, 145: 85-91. 